\title{
Myocardial infarction among male bus, taxi, and lorry drivers in middle Sweden
}

Per Gustavsson, Lars Alfredsson, Hans Brunnberg, Niklas Hammar, Robert Jakobsson, Christina Reuterwall, Piroska Östlin

\begin{abstract}
Objectives-The aim of the present casereferent study was to investigate the incidence of myocardial infarction among male professional drivers, taking the type of vehicles and area of residence into account.

Methods-The study base comprised all men aged 30-74 in five counties in middle Sweden during 1976-81 or 1976-84. Incident cases of the first episode of myocardial infarction were identified from registers of hospital admissions and causes of deaths. Referents were selected randomly from the study base. Information about occupation was obtained from the national censuses in 1970 and 1975. The possible impact from tobacco smoking and overweight were evaluated by simulations in combination with indirect data on these factors.
\end{abstract}

Results-The incidence of myocardial infarction was increased among bus drivers in Stockholm (relative risk $(\mathbf{R R})=$ $1.53,95 \%$ confidence interval (95\% CI) $1 \cdot 15-2 \cdot 05)$, and among taxi drivers both in Stockholm (RR 1.65, 95\% CI 1.30-2.11) and in the surrounding rural counties (RR 1.82, 95\% CI 1.17-2.82). A smaller increase was found among long distance lorry drivers, whereas the relative risk among short distance lorry drivers was close to unity. Indirect comparisons make it unlikely that the excess among bus drivers in Stockholm could be explained by uncontrolled confounding from tobacco smoking or overweight. A very high proportion (more than $80 \%$ ) of urban bus drivers in Sweden report a combination of high psychological demands and low control at work.

Conclusions-Different types of drivers are at different risk of myocardial infarction. Bus drivers in urban areas seem to be at an increased risk, which is unlikely to be explained by uncontrolled confounding from tobacco smoking or overweight. Psychosocial work conditions may play a part in the increased incidence of myocardial infarction among urban bus drivers and should be investigated further.

(Occup Environ Med 1996;53:235-240)

Keywords: job strain; myocardial infarction; occupational diseases; drivers
An increased risk for myocardial infarction has been reported in several studies of professional drivers ${ }^{1-7}$ but there are also some studies where this was not found. ${ }^{8-12}$ The evidence for an increased risk of myocardial infarction seems to be stronger among bus drivers ${ }^{13-7}$ than among other groups of drivers. Some of the negative epidemiological findings may be explained by methodological shortcomings of the studies. A recent Swedish investigation indicated that bus driving in urban areas is associated with an increased risk of myocardial infarction, although no increased risk was found among bus drivers in rural areas. ${ }^{3}$

Traditional risk factors for myocardial infarction include tobacco smoking, increased blood lipids, and hypertension. Hereditary factors and overweight also play a part in assessing the risk of developing myocardial infarction. Further, low physical activity at work or during leisure time, cold, and heat have been proposed as risk factors for myocardial infarction. ${ }^{13} \mathrm{~A}$ few chemical occupational exposures have been associated with an increased risk of myocardial infarction, among them combustion products. ${ }^{14}$ It is not known if this increased risk is due to any specific chemical such as carbon monoxide or polycyclic aromatic hydrocarbons (PAHs) ${ }^{14}$ and neither is it known if exposure to motor exhaust is of relevance for the increased risk of myocardial infarction among professional drivers. A combination of high psychological demands and low control at work (job strain) has been proposed as being associated with an increased risk of developing coronary heart disease. This theory, the Karasek-Theorell hypothesis, ${ }^{15}$ has gained support from several epidemiological studies; see for example, a recent review by Schnall and Landsbergis. ${ }^{16}$

The aim of the present study was to investigate the risk of myocardial infarction among professional drivers in Sweden, taking into account the types of vehicles (buses, taxis, long and short distance lorries) and urban or rural areas of residence. Indirect data on smoking, overweight, and job demands and control at work were used to assess the possible influence from these factors on the relative risks (RRs) found. The study was restricted to men as very few infarctions had occurred among female drivers in the studied areas.

\section{Material and methods}

The study base comprised the male population aged $30-74$ in five counties in middle Sweden: Uppsala, Södermanland, Gävleborg, 
and Kopparberg during 1976-81, and Stockholm county during 1976-84. The county of Stockholm represents an urban area whereas the other four counties mainly include rural areas. The study base was restricted to people holding the same type of job for at least five years. The RR for myocardial infarction among different types of drivers compared with other gainfully employed men was studied by case-referent methods.

\section{IDENTIFICATION OF CASES AND REFERENTS}

Incident cases of a first episode of myocardial infarction (International Classification of Diseases, eighth revision (ICD-8) code 410) were identified by the combined use of a central register of hospital admissions and the national registry of causes of deaths. Referents were selected randomly from the study base. They were frequency matched to the cases for age (five year age groups), year of admission, and death of the cases. The procedure has been described in detail earlier, ${ }^{17}$ and the process for finding of cases has been validated. ${ }^{1819}$

\section{DATA ON OCCUPATION}

Data on occupation (classified according to the Nordic standard classification of occupations) and industry code (according to the Swedish standard industrial classification of economic activities) from the censuses in $\mathbf{1 9 7 0}$ and 1975 were linked to cases and referents by the civil registration number, unique to every Swedish citizen. Bus, taxi, and short and long distance lorry drivers were identified from the codes for occupation and type of industry. Short distance lorry drivers perform local deliveries within an area corresponding to a large city with suburbs, whereas long distance lorry drivers perform intercity and international transportation of goods.

The study was restricted to people holding the same type of job in the same industry in the censuses of both 1970 and 1975 to avoid the influence from short term employed people who could be expected to distort any relation between occupational factors and the rate of myocardial infarction. Thus, all drivers in the study had had the same type of driving job for at least five years. Table 1 shows the number of cases and referents.

\section{ANALYTICAL METHODS}

The RR (incidence rate ratio) of developing myocardial infarction among drivers compared with other gainfully employed men was calculated according to the Mantel-Haenszel

Table 1 Number of cases and referents subdivided by type of driver and county

\begin{tabular}{|c|c|c|c|c|}
\hline \multirow[b]{2}{*}{ Occupation * } & \multicolumn{2}{|c|}{ Stockholm } & \multicolumn{2}{|c|}{$\begin{array}{l}\text { Uppsala, Gävleborg, } \\
\text { Södermanland, Kopparberg }\end{array}$} \\
\hline & Cases & Referents & Cases & Referents \\
\hline $\begin{array}{l}\text { Bus drivers } \\
\text { Taxi drivers } \\
\text { Long distance lorry drivers } \\
\text { Short distance lorry drivers } \\
\text { All occupations }\end{array}$ & $\begin{array}{r}70 \\
101 \\
112 \\
27 \\
4105\end{array}$ & $\begin{array}{r}141 \\
196 \\
270 \\
81 \\
13066\end{array}$ & $\begin{array}{r}22 \\
34 \\
98 \\
16 \\
2741\end{array}$ & $\begin{array}{r}50 \\
51 \\
211 \\
45 \\
7391\end{array}$ \\
\hline
\end{tabular}

*Same occupation in 1970 and 1975 procedure $^{20}$ allowing for differences in age (five year age groups), calendar year (three year periods), and county of residence.

\section{SMOKING HABITS AND OVERWEIGHT}

Individual data on factors, other than age and area of residence, that might confound the relation between the rate of myocardial infarctions and occupation were not available. Data on smoking and overweight from other investigations of drivers were used to assess the possible impact of these factors. The potential influence on the rate of myocardial infarction from tobacco smoking and overweight was evaluated by simulations, assuming different distributions of these risk factors among the drivers and the general population.

The calculations of the impact of smoking and overweight were analogous to a procedure previously developed for lung cancer and smoking, ${ }^{21}$ and were performed in the following way.

The incidence of myocardial infarction in a population may be calculated as a weighted sum of the incidence among non-smokers and smokers, with the proportions of smokers and non-smokers as weights:

$$
N S^{\star} a+S^{\star} a{ }^{\star} R R=I
$$

where: NS = the proportion of non-smokers, $a=$ the baseline incidence of myocardial infarction among non-smokers, $S=$ the proportion of smokers $(=1-N S), R R=$ the relative risk for myocardial infarction among smokers $v$ non-smokers, $\mathrm{I}=$ the resulting incidence of myocardial infarction in the population.

If the proportion of smokers were altered, the resulting incidence I would change. If the incidence associated with the first proportion of smokers were $I_{1}$, and the second incidence were $I_{2}$ the ratio $I_{2} / I_{1}$, which may be calculated without knowledge of the baseline incidence $a$, would express how much higher (or lower) the incidence of myocardial infarction gets with the second proportion of smokers. The unadjusted $R R$ for myocardial infarction was divided by the ratio $I_{2} / I_{1}$ to obtain the smoking-adjusted $R R$.

Analogous calculations were performed for the effect of overweight. A multiplicative interaction between the risk factors was assumed when the relative risks were adjusted for the combined effects from smoking and overweight.

The rate of myocardial infarction among smokers $v$ non-smokers has been investigated in several studies, and the relative risk that could be associated with smoking varies with different factors, like quantity smoked, age range, population, and whether ex-smokers have been included among the non-smokers or not. From the scientific literature, the rate of myocardial infarction was estimated to be 1.7 times higher among daily smokers than among non-smokers and exsmokers combined. ${ }^{22}$ This was the RR used in the simulations when correcting for differences in smoking habits. The rate of myocardial infarction in moderately overweight people (body mass index (BMI) $25 \cdot 1-29 \cdot 9)$ was estimated to be $13 \%$ higher 
Table 2 Relative risk (RR) of developing myocardial infarction among male drivers in Stockholm and four surrounding rural counties

\begin{tabular}{|c|c|c|}
\hline & Stockholm & $\begin{array}{l}\text { Uppsala, Södermanland, } \\
\text { Gävleborg, Kopparberg }\end{array}$ \\
\hline Driver group & $R R^{*}(95 \% C I)$ & $R R^{*}(95 \% C I)$ \\
\hline $\begin{array}{l}\text { Bus drivers } \\
\text { Taxi drivers } \\
\text { Long distance lorry drivers } \\
\text { Short distance lorry drivers }\end{array}$ & $\begin{array}{l}1.53(1.15-2.05) \\
1.65(1.30-2 \cdot 11) \\
1.31(1.05-1.64) \\
1.06(0.69-1.65)\end{array}$ & $\begin{array}{l}1.17(0.71-1.94) \\
1.82(1.17-2.82) \\
1.24(0.97-1.58) \\
0.94(0.53-1.68)\end{array}$ \\
\hline
\end{tabular}

^Relative risk adjusted for age, calendar period, and county.

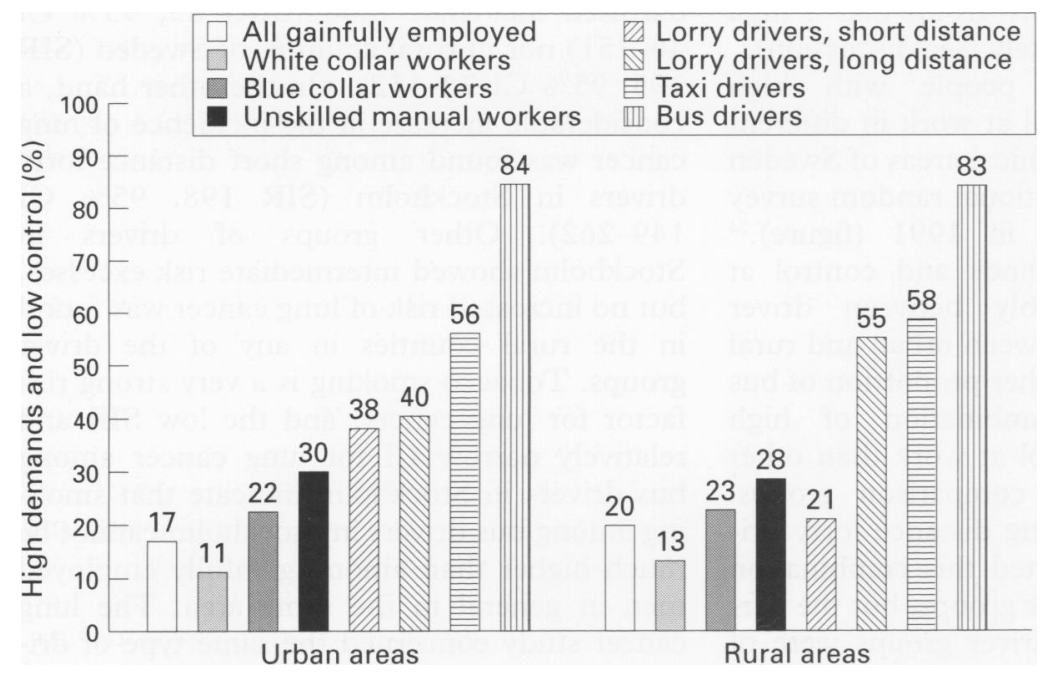

Percentage of men with high demands and low control at work in different occupations and geographical areas in Sweden (calculated from a national survey ${ }^{24}$ )

than among people with a normal BMI, and heavily overweight people $(\mathrm{BMI}>30)$ were considered to be at $50 \%$ greater risk of myocardial infarction. ${ }^{23}$

\section{PSYCHOSOCIAL WORK ENVIRONMENT}

No data on the psychosocial work environment were available for the study subjects. Self reported data on the psychosocial work environment in different occupations were obtained from a national survey investigation performed in 1991. ${ }^{24}$ Questions on different aspects of psychological job demands and job decision latitude (control) were aggregated to indices of demands and control, respectively, according to the principles outlined by Karasek and Theorell. ${ }^{15}$ The questions that were used to reflect psychological job demands were: do you have to skip lunch, work overtime, or take jobs home; is the work so stressful that you can't talk or think of anything else other than the work; are there parts of time when you just wait and are prepared for anything to happen; does the work demand your full attention; do you have to look attentively at something during work, or it goes wrong; are you satisfied or dis- satisfied with working hours?

Decision latitude was coded from the following questions: do you have influence over the work pace; can you talk to colleagues during work; can you take short breaks; can you decide when different tasks should be done; do you take part when your work is organised; do you have a feeling of influence over the job; do you have a feeling of freedom $v$ lack of freedom at work?

The quantitative responses to each of these questions were dichotomised and the number of positive responses were added to form indices of job demands and decision latitude for every man in the survey. All men were then classified as either low or high in demands and decision latitude, and the percentage of men reporting both high demands and low decision latitude was calculated for each occupation.

\section{Results}

MYOCARDIAL INFARCTION

The RR for myocardial infarction differed considerably between groups of drivers and also between urban and rural drivers (table 2). An increased incidence was found among bus drivers in Stockholm and among taxi drivers in both areas, compared with all gainfully employed men. Long distance lorry drivers who lived in Stockholm had a moderately increased incidence, whereas the incidence among short distance lorry drivers was equal to the average among gainfully employed men.

\section{TOBACCO SMOKING AND OVERWEIGHT}

Table 3 shows the decrease in the RRs that would result from successively increasing assumed proportions of daily smokers and overweight people among the bus drivers in Stockholm. Each of the columns in the table represents the effects of increasing proportions of daily smokers among the bus drivers. The baseline in the left hand column corresponds with the mean percentage of daily smokers among men in Stockholm during 1983, 34\%. ${ }^{25}$ Similar calculations were performed for overweight, represented by the rows in the table. A population based national survey investigation in 1988-9 indicated that the proportions of people of low or normal weight, moderate overweight, and heavy overweight were $63 \%$, $32 \%$, and $4.5 \%$ respectively. ${ }^{26}$ These percentages were used as a baseline in table 3 . The other rows represent increasing proportions of overweight people among the bus drivers. Only the more extreme combinations of overweight and excess smoking reduces the RR to a nonsignificant level.

Table 3 Calculated RRs (95\% CI) for myocardial infarction among bus drivers in Stockholm, assuming different distributions of smoking and overweight among drivers and the general population

\begin{tabular}{|c|c|c|c|c|c|c|}
\hline \multicolumn{3}{|c|}{ Distribution (\%) of BMI among the drivers } & \multirow{2}{*}{\multicolumn{4}{|c|}{ Daily smokers among the drivers (\%) }} \\
\hline Normal & Over- & Heavily & & & & \\
\hline weight & weight & overweight & $34^{\star}$ & 40 & 50 & 60 \\
\hline $\begin{array}{l}63 \\
50 \\
40\end{array}$ & $\begin{array}{l}32 \\
40 \\
45\end{array}$ & $\begin{array}{l}4 \cdot 5^{\star} \\
10 \\
15\end{array}$ & $\begin{array}{l}1.53(1.15-2.05) \\
1.48(1.11-1.98) \\
1.44(1.08-1.93)\end{array}$ & $\begin{array}{l}1.48(1.11-1.98) \\
1.43(1.07-1.92) \\
1.39(1.04-1.86)\end{array}$ & $\begin{array}{l}1.40(1.05-1.88) \\
1.36(1.02-1.82) \\
1.32(0.99-1.77)\end{array}$ & $\begin{array}{l}1.33(1.00-1.79) \\
1.29(0.97-1.73) \\
1.25(0.94-1.68)\end{array}$ \\
\hline
\end{tabular}

^Similar to the general population. 
Similar calculations were performed for the other groups of drivers. Also among taxi drivers, both in Stockholm and in the rural counties, large excesses of tobacco smoking and overweight must be assumed to reduce the $R R$ substantially. The intermediate excess risk noted among the long distance lorry drivers in Stockholm attenuates rapidly towards unity as increasing smoking and overweight are assumed. The results of adjustments for smoking and overweight are shown for bus drivers only, as it is only for this group that a high excess of smokers is unlikely (see discussion).

The proportion of people with high demands and low control at work in different occupations and geographical areas of Sweden was calculated from a national random survey investigation performed in 1991 (figure). ${ }^{24}$ The perception of demands and control at work varied considerably between driver groups but not much between urban and rural areas. A considerably higher proportion of bus drivers reported a combination of high demands and low control at work than other driver groups and the comparison groups. Also, taxi drivers and long distance lorry drivers in rural areas reported this combination more often than the other groups, but the percentages for the other driver groups were of the same magnitude as the mean for unskilled manual workers.

\section{Discussion}

An increased incidence of myocardial infarction was found among bus drivers in Stockholm and among taxi drivers both in Stockholm and in the rural counties. A slight excess was present also among long distance lorry drivers. We discuss possible sources of error in the estimates of the RR, as well as the possible impact of tobacco smoking, overweight, and other factors.

Occupation was coded from census data, and the occupational title may have been miscoded for some men. As the same occupational code was required both in 1970 and in 1975 it is likely that this type of misclassification was small. Cases of myocardial infarction were identified through the combined use of hospital admission registers and death records. The national registry of causes of death records practically all deaths occurring among people who live in Sweden, and the losses of cases from this source would be very small. The procedure for finding live cases has been validated. ${ }^{18} 19$

The clinical diagnosis of myocardial infarction is subject to misclassification due to problems in diagnostic criteria, etc. However, this type of misclassification is likely to be unrelated to occupation and give a bias of the RR towards unity.

A central question is to what extent the increased incidence of myocardial infarction among some driver groups may be explained by increased smoking habits, overweight, or other risk factors for myocardial infarction that might confound the studied relations.

A population survey investigation per- formed in $1988-91^{26}$ indicated that $36 \%$ of lorry drivers and taxi drivers smoked daily whereas $28 \%$ of gainfully employed men in the general population in Sweden smoked daily. A recently presented investigation on incidence of lung cancer among professional drivers in Sweden was based on 102428 male drivers identified from the census of $1970 .{ }^{27}$ The study showed no increased risk among male bus drivers compared with all gainfully employed men, neither in Stockholm (standardised incidence ratio (SIR) $83,95 \% \mathrm{CI}$ 46-151) nor in rural counties of Sweden (SIR $105,95 \%$ CI $72-152$ ). On the other hand, a considerable increase in the incidence of lung cancer was found among short distance lorry drivers in Stockholm (SIR 198, 95\% CI 149-262). Other groups of drivers in Stockholm showed intermediate risk excesses, but no increased risk of lung cancer was found in the rural counties in any of the driver groups. Tobacco smoking is a very strong risk factor for lung cancer, and the low SIR and relatively narrow CI for lung cancer among bus drivers in Stockholm indicate that smoking among bus drivers in Stockholm cannot be much higher than among gainfully employed men in general in the same area. The lung cancer study concerned the same type of drivers in the same area and comprised to a large extent the same people as the present study, although in the lung cancer study no restriction was made for minimum employment time. Tobacco smoking has never been allowed on Swedish buses, neither among passengers nor among drivers, although lorry drivers may smoke while driving. These data, taken together, indicate that there probably is an excess of daily smokers among Swedish lorry and taxi drivers, but such an excess among bus drivers in Stockholm seems highly unlikely.

No data on the frequency of obesity among bus drivers in Stockholm were available. The calculations in table 3 indicated, however, that even if a threefold excess of heavily overweight people is assumed among the drivers there still remains a significantly increased incidence of myocardial infarction, as long as a considerable increase in smoking is not also assumed. Against the background of the findings in the lung cancer study cited this seems very unlikely. The moderate excess of myocardial infarction among the long distance lorry drivers was so small that excess smoking habits and possibly also overweight well may explain the increased risk. This is possibly also true for the taxi drivers, although the RR found was higher-and even higher frequencies of smoking and overweight must be assumed, possibly in combination with physical inactivity. For the bus drivers it does not seem likely that the excess may be explained by tobacco smoking or overweight.

Bus drivers have lower physical activity in their job than several other occupational groups. However, this applies to bus drivers in rural areas as well, in whom no increased risk of myocardial infarction was found. Bus drivers 
in Gothenburg reported a higher level of physical activity in leisure time than other occupational groups. ${ }^{4}$ This indicates that lower physical activity in leisure time or a sedentary job may seem less likely explanations for the increased rate of myocardial infarction among the bus drivers in the present study.

A combination of high demands and low control at work was common among bus drivers and also among taxi drivers. Long and short distance lorry drivers were, however, closer to the mean for other occupational groups in this respect. This type of psychosocial work load has been shown to be associated with an increased rate of myocardial infarction. ${ }^{16}$ In the present study, on the whole the same groups that reported high demands and low control at work also had an increased risk of myocardial infarction. The bus drivers' work is characterised by contact with many passengers and strict time schedules. Further investigations are needed to clarify what specific factors in the psychosocial work environment are underlying the drivers' perception of low control and high demands.

Lower socioeconomic status is associated with an increased rate of myocardial infarction. ${ }^{28}$ However, there are no indications that bus drivers would have a lower socioeconomic status than lorry drivers and comparisons between the driver groups do not indicate socioeconomic status as a probable explanation for the present findings.

Professional drivers are often assumed to be exposed to motor exhaust, but very few investigations of exposure levels have been published. Probably, the exposure levels vary considerably between types of vehicles, urban and rural areas, and also over calendar periods reflecting changes in work conditions, fuel types, garage ventilation, etc. A study of bus drivers in Paris and Bordeaux indicated that the drivers' exposure to common air pollutants like carbon monoxide, nitrous dioxide and benzo(a)pyrene were of the same magnitude as samples of the general air in more polluted parts of the cities. ${ }^{29}$ The reported concentrations were considerably lower than occupational exposure limits for the respective substances. A study of lorry drivers in Geneva indicated that exposure to total dust was higher among drivers in urban than in rural areas, 0.3 and $0.1 \mathrm{mg} / \mathrm{m}^{3}$ as full shift time weighted averages. ${ }^{30}$ These concentrations are low compared with occupational exposure limit values.

These data indicate that professional drivers in urban areas are exposed to air pollution that corresponds with the more polluted parts of a city. It is questionable if exposures of this magnitude can be associated with an increased risk of myocardial infarction, taking into account the relatively weak support for motor exhausts and combustion products as risk factors for myocardial infarction. ${ }^{14}$ Investigations of occupational groups with a very high exposure to combustion products like chimney sweeps, ${ }^{31}$ gas manufacturing workers, ${ }^{32}$ and waste incineration workers ${ }^{33}$ show excesses of myocardial infarction of roughly the same magnitude or even lower than that found among the bus drivers.

Several investigations show that exposure to lead may be associated with increased blood pressure, ${ }^{14}$ which is a risk factor for myocardial infarction. For the past 50 years, buses in Stockholm have been powered by diesel oil, which contains no lead. Thus, the increased incidence of myocardial infarction among bus drivers in Stockholm cannot be attributed to exposure to lead.

The present findings correspond well with those from a study of risk factors for myocardial infarction among bus and lorry drivers in northern Sweden. Bus drivers more often reported low control and high demands than lorry drivers and controls from the general population. ${ }^{34}$ An increased risk of myocardial infarction was found among Danish city bus drivers, and the risk was highest among drivers working in central urban areas. ${ }^{6}$

Our results also correspond well with those of a prospective population survey in Gothenburg in Sweden. The risk of myocardial infarction was tripled among 103 bus and tram drivers, with individual adjustment for smoking, blood pressure, blood lipid concentrations, physical activity, and body weight. ${ }^{4}$ In the same study, taxi drivers had a doubled risk of myocardial infarction, although the increased risk for taxi drivers was not significant. No excess risk was found among lorry drivers.

In conclusion, this study showed an increased incidence of myocardial infarction among bus drivers in Stockholm and among taxi drivers both in Stockholm and in the surrounding four counties, compared with other gainfully employed men. As direct information on several traditional risk factors as well as characteristics of the work place is lacking, the cause of this increase is uncertain. However, indirect comparisons show that the excess of myocardial infarction among the bus drivers in Stockholm is not likely to be explained by increased smoking or overweight. Sedentary job, lower physical activity in leisure time, socioeconomic status, and exhaust exposure also seem unlikely as main explanations for this increased risk. Bus and taxi drivers more often reported psychosocial job strain than other drivers and men in other occupations. Characteristics of the psychosocial work environment should be a key issue in future research on the aetiology of myocardial infarction in professional drivers, but more information on lifestyle factors as well as chemical work place characteristics would also be needed for a better understanding of the causes of myocardial infarction among professional drivers.

We thank Tomas Hemmingsson and Hannu Kiviranta for computer analyses and Anders Wikman, Alf Andersson, and Eva Lundin Högstorp at Statistics Sweden for access to population survey data and kind assistance. This report is a part of a programme directed towards identification and prevention of work related hazards among professional drivers. The programme is under supervision of a referance group with repregramme is under supervision of a referance group with representatives from trade unions, employers, company health care organisations of the Swedish transport trade, and the factory inspectorate. We thank the representatives of these organisations for support of the progran
Stockholm County Council. 
1 Morris JN, Heady JA, Raffle PAB, Roberts CG, Parks JW. Coronary heart-disease and physical activity of work. Lancet 1953;1053-7.

2 Hedberg G, Jacobsson KA, Langendoen S, Nyström L. Mortality in circulatory diseases, especially ischemic heart disease, among Swedish professional drivers: a retrospective cohort study. $\mathcal{F}$ Hum Ergol (Tokyo) 1991;20: $1-5$.

3 Alfredsson L, Hammar N, Hogstedt C. Incidence of myocardial infarction and mortality from specific causes among bus drivers in Sweden. Int $\mathcal{F}$ Epidemiol 1993;22: 57-61.

4 Rosengren A, Anderson K, Wilhelmsen L. Risk of coronary heart disease in middle-aged male bus and tram drivers compared to men in other mccupations: a prospective study. Int $\mathcal{F}$ Epidemiol 1991;20:82-7.

5 Michaels D, Zoloth SR. Mortality among urban bus drivers. Int $\mathcal{F}$ Epidemiol 1991;20:399-404.

6 Netterström B, Suadicani P. Self-assessed job satisfaction and ischemic heart disease mortality: a 10 year follow up of urban bus drivers. Int $\mathcal{F}$ Epidemiol 1993;22:51-6.

7 Tuchsen F, Bach E, Marmot M. Occupation and hospitalization with ischaemic heart diseases: a new nationwide surveillance system based on hospital admissions. Int $\mathcal{f}$ Epidemiol 1992;21:450-9.

8 Ahlbom A, Theorell T. Hjärtinfarkt hos trafikpersonal vid Stockholms lokaltrafik. Läkartidningen 1980;77:3472-3.

9 Hansen ES. A follow-up study on the mortality of truck drivers. Am F Ind Med 1993;23:81 1-21.

10 Luepker RV, Smith ML. Mortality in unionized truck drivers. $f$ Occup Med 1978;20:677-82.

11 Paradis G, Theriault G, Tremblay C. Mortality in a historical cohort of bus drivers. Int $\mathcal{f}$ Epidemiol 1989;18: 397-402.

12 Balarajan $R$, McDowall ME. Professional drivers in London: a mortality study. Br 7 Ind Med 1988;45:483-6.

13 Kristensen TS. Cardiovascular diseases and the work environment. A critical review of the epidemiologic literature

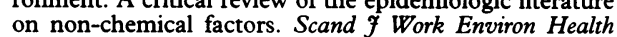
1989;15:165-79.

14 Kristensen TS. Cardiovascular diseases and the work environment. A critical review of the epidemiologic literature on chemical factors. Scand $f$ Work Environ Health 1989;15:245-64.

15 Karasek R, Theorell T. Healthy work. New York: Basic Books, 1990.

16 Schnall PL, Landsbergis PA. Job strain and cardiovascular disease. Annu Rev Public Health 1994;15:381-411.

17 Hammar N, Alfredsson L, Smedberg M, Ahlbom A Differences in the incidence of myocardial infarction among occupational groups. Scand $\mathcal{f}$ Work Environ Health 1992;18:178-85.

18 Ahlbom A. Acute myocardial infarction in Stockholm-a medical information system as an epidemiological tool. medical information system
Int $\mathcal{f}$ Epidemiol 1978;7:271-6.

19 Hammar N, Nerbrand C, Ahlmark G, Tibblin G,
Tsipogianni A, Johannson S, et al. Identification of cases of myocardial infarction: hospital discharge data and mortality data compared to myocardial infarction community tality data compared to myocardial infarction

20 Breslow NE, Day NE. Statistical methods in cancer research. Vol 1. The analysis of case-control studies. Lyon: International Agency for Research on Cancer Sci Publ, 1980. 32.

21 Axelson O. Aspects on confounding in occupational health epidemiology. Scand $f$ Work Environ Health 1978;4 98-102.

22 US Surgeon General. Smoking and health: a report of the surgeon general 1979. Cincinnati: US Department of Health, Education, and Welfare, 1979. (DHEW Publication No (PHS) 79-50066.)

23 Waaler HT. Height, weight and mortality. The Norwegian experience. Acta Medica Scandinavica Supplements 1984; 67:1-56.

24 Statistics Sweden. Arbetsmiljön 1988/91. Statistiska rapporter, Am68 SM 9201. Stockholm: Statistics Sweden. 1992

25 National Board of Health and Welfare. Tobaksvanor Sverige. Socialstyrelsen redovisar: 1986:9. Stockholm: National Board of Health and Welfare, 1986.

26 Statistics Sweden. Teknisk rapport avseende 1984/85, 1986/87, 1988/89 års undersökning av levnadsförhållanden. Appendix $n r$ 13. Stockholm: Statistics Sweden. 1991.

27 Jakobsson R, Gustavsson P, Lundberg I. Lung cancer among professional drivers in Sweden [abstract]. 10th International Symposium on Epidemiology in Occupational Health, Sept 21-23. Como, Italy: International Congress on Occupational Health, Scientific Committee on Occupational Epidemiology, 1994.

28 Marmot M, Theorell T. Social class and cardiovascular disease: the contribution of work. Int $\mathcal{F}$ Health Serv 1988; 18:659-74.

29 Limasset J-C, Diebold F, Hubert G. Assessment of bus drivers' exposure to the pollutants of urban traffic. Sci Total Environ 1993;134:39-49. (In French.)

30 Guillemin MP, Herrera H, Huynh CK, Droz PO, Duc TV. Occupational exposure of truck drivers to dust and polynuclear aromatic hydrocarbons: a pilot study in Geneva, Switzerland. Int Arch Occup Environ Health 1992;63:439-47.

31 Gustavsson P, Gustavsson A, Hogstedt C. Excess mortality among Swedish chimney sweeps. Br $\mathcal{F}$ Ind Med 1987 44:738-43.

32 Gustavsson P, Reuterwall C. Mortality and incidence of cancer among Swedish gas workers. $\mathrm{Br} \mathcal{F}$ Ind Med 1990; 47:169-74.

33 Gustavsson P. Mortality among workers at a municipal waste incinerator. Am 7 Ind Med 1989;15:245-53.

34 Hedberg G, Jacobsson KA, Janlert U, Langendoen S. Risk indicators of ishemic heart disease among male professional drivers in Sweden. Scand $\mathcal{f}$ Work Environ Health 1993;19:326-33.

\section{Correspondence and editorials}

Occupational and Environmental Medicine welcomes correspondence relating to any of the material appearing in the journal. Results from preliminary or small scale studies may also be published in the correspondence column if this seems appropriate. Letters should be not more than 500 words in length and contain a minimum of references. Tables and figures should be kept to an absolute minimum. Letters are accepted on the understanding that they may be subject to editorial revision and shortening.

The journal also publishes editorials which are normally specially commissioned. The Editor welcomes suggestions regarding suitable topics; those wishing to submit an editorial, however, should do so only after discussion with the Editor. 